\title{
The Management of Spontaneous Cerebrospinal Fluid Rhinorrhea in Patients at Risk for Increased Intracranial Tension
}

\author{
Ahmed Farahat ${ }^{1}$, Hesham Elshitany ${ }^{2}$, Mohamed A. R. Soliman ${ }^{2}$ \\ ${ }^{1}$ Ear, Nose, and Throat Department, Cairo University, Giza, Egypt \\ ${ }^{2}$ Neurosurgery Department, Cairo University, Giza, Egypt \\ Email: moh.ar.sol@kasralainy.edu.eg
}

How to cite this paper: Farahat, A., Elshitany, H. and Soliman, M.A.R. (2020) The Management of Spontaneous Cerebrospinal Fluid Rhinorrhea in Patients at Risk for Increased Intracranial Tension. Open Journal of Modern Neurosurgery, 10, 1-8. https://doi.org/10.4236/ojmn.2020.101001

Received: October 1, 2019

Accepted: November 4, 2019

Published: November 7, 2019

Copyright () 2020 by author(s) and Scientific Research Publishing Inc. This work is licensed under the Creative Commons Attribution International License (CC BY 4.0).

http://creativecommons.org/licenses/by/4.0/

\begin{abstract}
Introduction: The exact pathophysiology of spontaneous CSF rhinorrhea is not always understood in some patients. Idiopathic intracranial hypertension (IIH) is now recognized as one of the causes of spontaneous CSF leak in the neurosurgical and ENT literature. Our aim was to set a management protocol for such cases according to the same setting intracranial tension (ICT). Methods: We prospectively managed patients with spontaneous CSF rhinorrhea who were admitted to our hospital between $1^{\text {st }}$ of January 2014 and $31^{\text {st }}$ of December 2017 with a prespecified treatment algorithm. Patients with a history of previous cranial or nasal surgery, trauma, skull base congenital malformations were excluded from the study. The patient's demographics, clinical data, comorbidities, body mass index (BMI), first time or recurrent leakage and duration of the leak were collected. Results: 41 patients, 35 females and 6 males, presented with spontaneous CSF rhinorrhea with a mean BMI of $38 \pm 4.16 \mathrm{Kg} / \mathrm{m}^{2}$. The mean pre-operative ICT manometry was $17.2 \pm 5.9$ $\mathrm{cmH}_{2} \mathrm{O}$ (range, $10-26 \mathrm{cmH}_{2} \mathrm{O}$ ). $43.9 \%$ of the patients were found to have an increased ICT $\left(\geq 20 \mathrm{cmH}_{2} \mathrm{O}\right)$ and underwent a permanent CSF diversion at the same setting of the endoscopic repair. None of the patients had a recurrence during the follow-up period. Conclusion: The prespecified treatment algorithm with measuring the ICT at the same setting of the endoscopic repair has a better result for control of spontaneous CSF rhinorrhea. This has led to no recurrence and decreased hospital stay.
\end{abstract}

\section{Keywords}

Spontaneous, Cerebrospinal (CSF) Rhinorrhea, Cerebrospinal (CSF) Leak, Endoscopic Repair, Cerebrospinal (CSF) Diversion 


\section{Introduction}

The cerebrospinal fluid (CSF) leakage from the subarachnoid space (SAS) into the paranasal sinuses and then to the nasal cavity is called CSF rhinorrhea. Most of the CSF rhinorrhea cases develop after an iatrogenic and accidental dura matter injury, although spontaneous and nontraumatic cases have been reported [1] [2].

The exact pathophysiology of spontaneous CSF rhinorrhea is not always understood in some patients [3]. Idiopathic intracranial hypertension (IIH) is now recognized as one of the causes of spontaneous CSF leak in the neurosurgical and ENT literature [4]-[10]. Also, some authors have suggested that primary spontaneous CSF leaks represent a form of idiopathic intracranial hypertension [4]-[10]. Some of the IIH patients might present only with CSF leak symptoms such as rhinorrhea, low tension headaches, or bacterial meningitis. The typical symptoms of IIH usually start a few weeks to months after the surgical CSF leak repair because of increased intracranial tension (ICT) [11]. Rarely, known patients with IIH with chronically raised ICT may develop CSF leak due to erosion of the skull base and development of meningocele [4]. Some authors recommend that lumbar puncture with manometry can be done just prior or after surgical repair to measure the ICT and whenever the ICT is high, temporary ICT lowering measures such as acetazolamide or lumbar drain are recommended [12] [13] [14]. These measures may temporarily seal the repair site, but due to a continuous high-pressure gradient, the defect will ultimately dehisce which occurs even later than 14 months post-repair [15] [16].

To achieve successful management of these patients, early recognition and permanent CSF diversion are required in cases of increased ICT. Our study aimed to prospectively apply a prespecified treatment algorithm on spontaneous CSF rhinorrhea cases and to report their outcome.

\section{Patients and Methods}

In this prospective study, all patients presented to the neurosurgery and ENT department at Cairo University hospitals between $1^{\text {st }}$ of January 2014 and $31^{\text {st }}$ of December 2017 with spontaneous CSF rhinorrhea were included in the study. Patients with a history of previous cranial or nasal surgery, trauma, skull base congenital malformations were excluded from the study. The study was approved by the ethical committee of the neurosurgery department, Cairo University. After the CSF leak was verified using $\beta-2$ transferrin and the site of CSF leak was identified using multi-slice thin-cut CT scan, CT metrizamide or cisternography, written consent was signed by all patients. The patient's demographics, clinical data, comorbidities, body mass index (BMI), first time or recurrent leakage and duration of the leak were prospectively collected from the charts. Patients with spontaneous CSF rhinorrhea were managed according to the prespecified algorithm (Figure 1). 


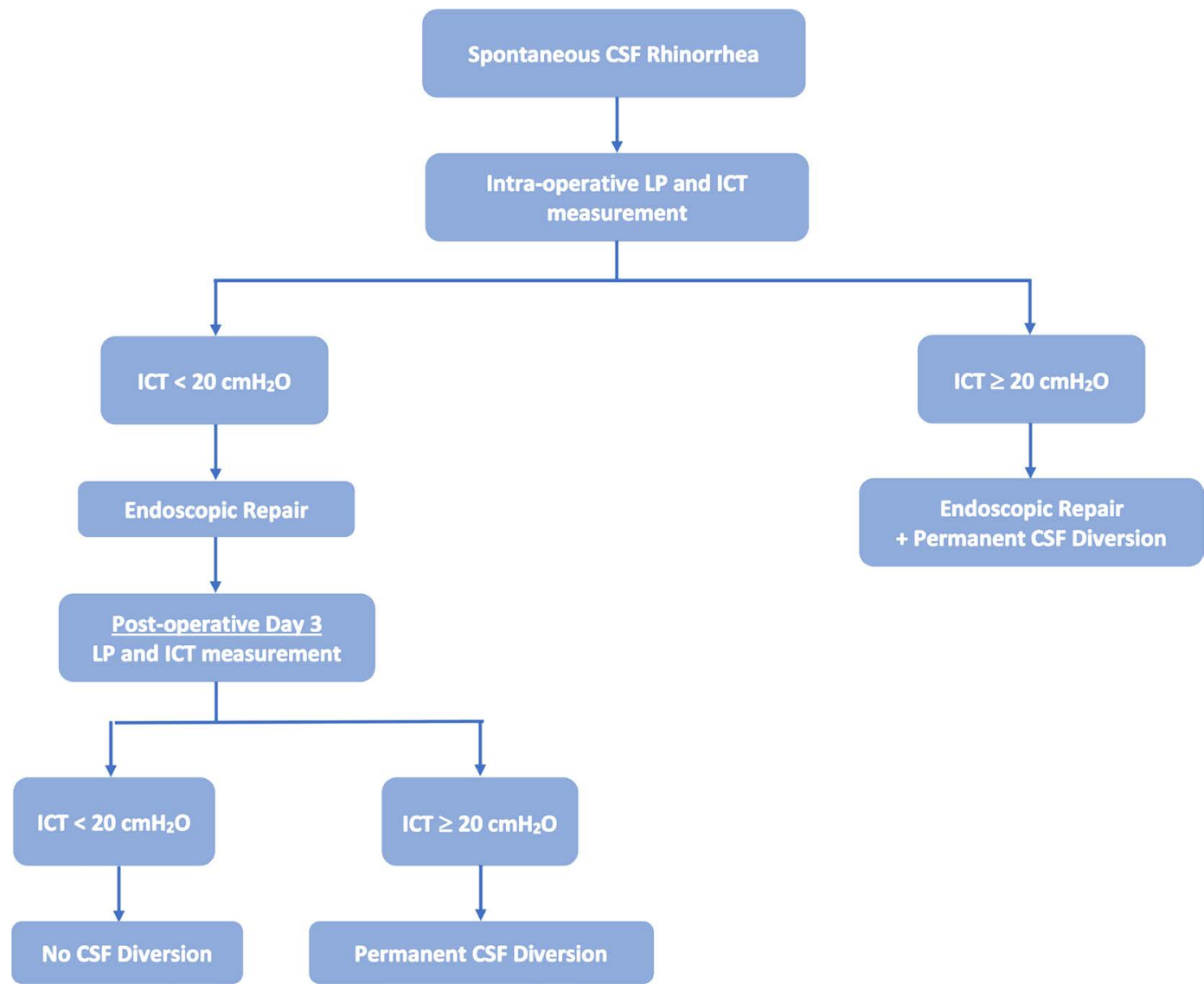

Figure 1. The proposed treatment algorithm.

\section{Management:}

After lumbar puncture was done and ICT was measured in the operating room, endoscopic endonasal repair of the defect was done. If the ICT was $\geq 20$ $\mathrm{cmH}_{2} \mathrm{O}$ before surgery, a permanent CSF diversion was done. While, if it was $<20 \mathrm{cmH}_{2} \mathrm{O}$, a lumbar puncture and ICT measurement was done three days after surgery. If the ICT increased $\geq 20 \mathrm{cmH}_{2} \mathrm{O}$ a permanent CSF diversion was done while if it still low, the patient was discharged and followed up in the outpatient clinic.

\section{Surgical Technique:}

The technique included an inlay or onlay free tissue grafts to patch the site of injury; entire exposure of the defect was essential. Multilayers technique including fascia lata, temporalis fascia, abdominal adipose tissue, septal or middle turbinate mucosa or composite grafts, periosteum, and perichondrium are all suitable grafting tissues. Whenever possible, the dural edges were undermined with a small elevator, and the edges of the graft were tucked between the dura and the bone. Fibrin glue or other biologic glue was used to increase the adhesiveness of the muscle or fascia graft. Then the graft was supported in place with layers of Gelfoam, followed by packing with bacitracin-impregnated sponge packing. Gelfoam prevented adherence of the packing material to the graft, preventing accidental avulsion when the packing is removed, 3 to 7 days after the surgery. If 
the fistula involved the cribriform plate, the mucosa and bone of the medial aspect of the middle turbinate were removed and the remaining mucoperiosteal flap was rotated to cover the defect or to cover a muscle or free fascial graft. The flap was then supported by Gelfoam and bacitracin impregnated gauze. In case of very large defect of the skull base, the Hadad-Bassagasteguy flap consisting of a septal mucoperichondrial/mucoperiosteal flap based on the posterior septal artery was used.

Follow-Up:

A brain CT scan was performed immediate post-operative and 2 weeks after surgery. Patients were followed up at 14 days, 3 months, 6 months and one year after surgery. There are six patients lost follow-up after 6 months after surgery.

\section{Statistical Analysis.}

All the data were prospectively collected and were reported as a mean value with standard deviation, range or percentages.

\section{Results}

41 patients were repaired endoscopically for spontaneous CSF rhinorrhea between $1^{\text {st }}$ of January 2014 and $31^{\text {st }}$ of December 2017. There was female predominance $(80.5 \%)$ in our study group with a mean age of $35.1 \pm 8.2$ years (age range, 22 - 62 years). The mean basal metabolic index (BMI) of our study group was $38 \pm 4.16 \mathrm{Kg} / \mathrm{m}^{2}$ (range, $27.1-46.3 \mathrm{Kg} / \mathrm{m}^{2}$ ). 9 patients had recurrent CSF rhinorrhea after the previous repair. All patients failed conservative treatment before surgery was indicated (full course of acetazolamide or intolerant to acetazolamide). The defect was found in the cribriform plate of ethmoid in 14 patients, frontal sinus in 7 patients, fovea ethmoidalis in 7 patients, sphenoid sinus in 6 patients, combined cribriform and fovea ethmoidalis in 4 patients, and sella turcica in 3 patients (Figure 2).

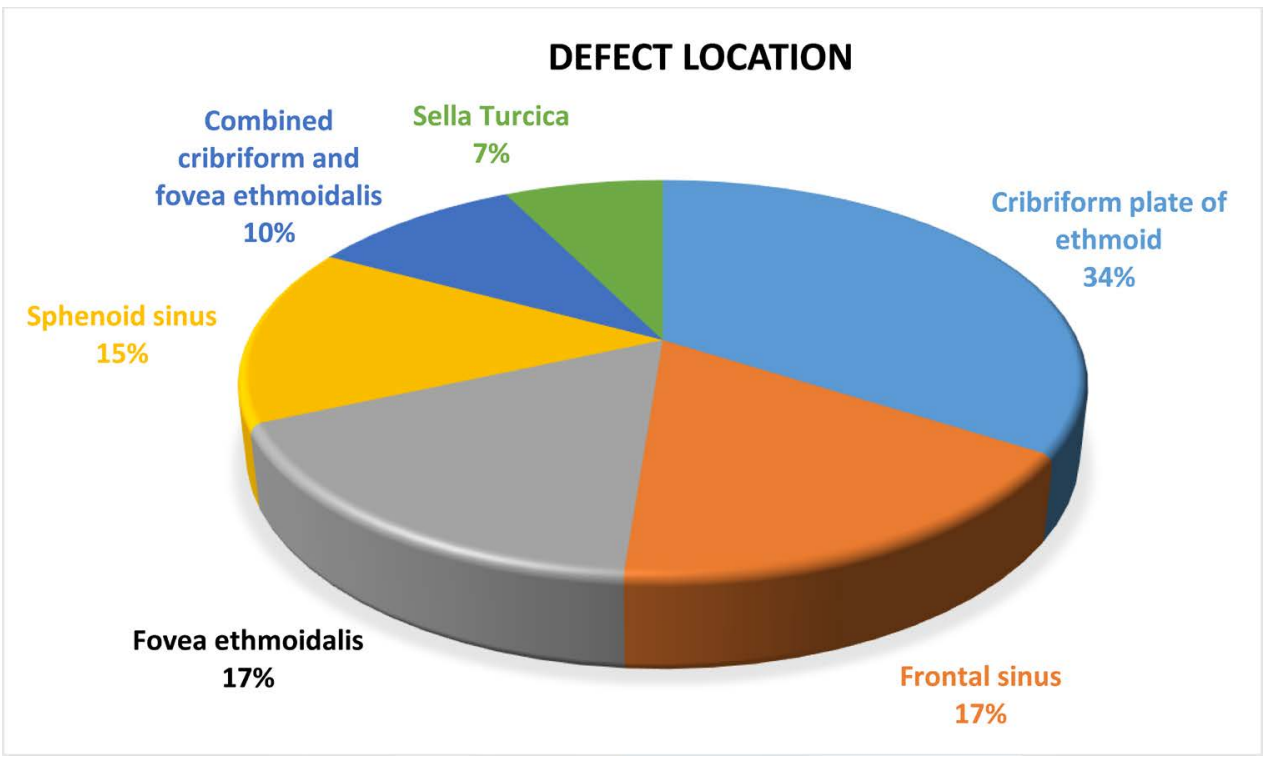

Figure 2. Pie chart showing the defect location distribution. 
The mean pre-operative ICT manometry was $17.2 \pm 5.9 \mathrm{cmH}_{2} \mathrm{O}$ (range, 10 $26 \mathrm{cmH}_{2} \mathrm{O}$ ). 18 patients (43.9\%) were found to have an increased ICT $\left(\geq 20 \mathrm{cmH}_{2} \mathrm{O}\right)$ before endoscopic repair and underwent a permanent CSF diversion at the same setting of the endoscopic repair. Out of the 23 patients that were not shunted, eight patients (34.8\%) developed an increased ICT $\geq 20 \mathrm{cmH}_{2} \mathrm{O}$ on measuring the opening pressure on day 3 post-surgery with a mean ICT of $29 \pm 5.5 \mathrm{cmH}_{2} \mathrm{O}$ (range, $23-39 \mathrm{cmH}_{2} \mathrm{O}$ ) and they underwent a permanent CSF diversion on day 3 - 5 post-repair. Therefore, 26 of $41(63.4 \%)$ were identified to have increased ICT and underwent permanent CSF diversion. The rest of the patients were discharged with no further intervention (Figure 3). All patients were repaired successfully using the endoscope and no revision surgery was required during a follow-up period of 12 months. Regarding postoperative complications, mild pneumocephalus occurred in 4 patients, intranasal adhesions in 2 patients, shunt migration in 2 patients and shunt infection in one patient.

\section{Discussion}

Spontaneous CSF rhinorrhea is a very challenging condition that neurosurgeons and ENT surgeons face in their practice especially in recurrent cases after surgical repair [12]. This is attributed to the failure of management of increased ICT rather than the failure of repair [3]. The pathophysiology behind the recurrence is that after the repair of the defect, there is an increased ICT creating a pressure gradient leading to CSF escape through the least resistance pathway [15]. Treating the increased ICT has an important adjuvant role to the repair of the defect in the management of such patients and is associated with a higher success rate [17]. The most important key factor in managing these patients is to early identify which patient that has an increased ICT requiring CSF diversion which in turn decrease the rate of recurrence [15].

A lumbar puncture with manometry can be done just prior or after surgical

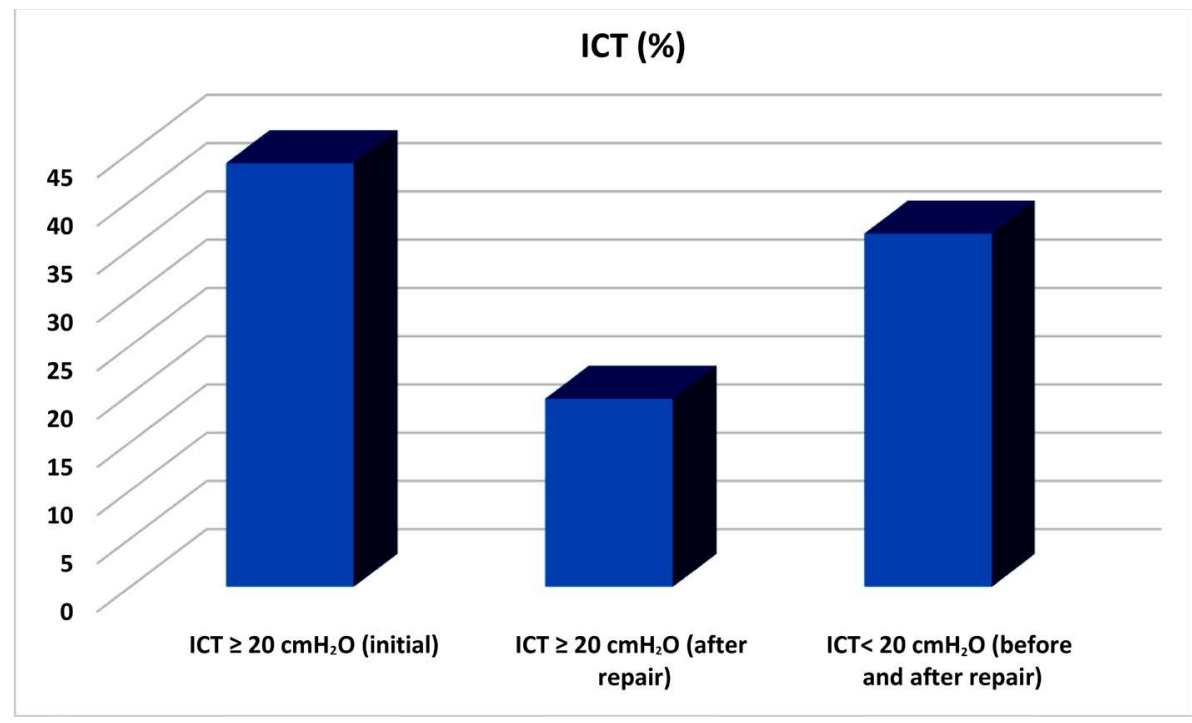

Figure 3. Bar chart showing the distribution (\%) of the patients according to the ICT. 
repair to measure the ICT and whenever the ICT is high, some authors recommended temporary ICT lowering measures such as acetazolamide or lumbar drain [12] [13] [14]. There is a lot of controversy around the efficacy of the use of lumbar drains after repair of CSF rhinorrhea [14] [18].

Temporary measures may temporarily seal the repair site, but due to a continuous high-pressure gradient, the defect will ultimately dehisce which occur even later than 14 months post-repair [15] [16]. Therefore, a permanent CSF diversion is recommended to prevent CSF leak recurrence in cases of increased ICT. Our series suggests that patients with increased ICT have an increased risk of recurrence can be prospectively identified. Therefore, for such patients, permanent CSF diversion is recommended either at the same setting of the repair or shortly after, which resulted in shorter hospital stay, and increased success rate with $0 \%$ recurrence. Also, using our proposed treatment algorithm will avoid risks associated with recurrent CSF rhinorrhea such as pneumocephalus and meningitis.

In our series, $63.4 \%$ had an increased intracranial tension $\left(\geq 20 \mathrm{cmH}_{2} \mathrm{O}\right)$ either before or after the repair which required a permanent CSF diversion, while the rest of the patients didn't require any CSF diversion procedure. Our $0 \%$ recurrence rate of CSF rhinorrhea is consistent with previous reports which are attributed to the control of ICT [19] [20]. Using our treatment algorithm, we can achieve an early diagnosis and treatment of associated increased ICT when present leading to decrease the recurrence rate.

\section{Limitation:}

Our study is not a randomized trial with a limited period of follow-up. It is a single-center experience with small sample size. Also, the specificity, sensitivity, and cost-effectiveness of our management algorithm remain to be elucidated.

\section{Conclusion}

Evidence of increased ICT can be detected at the same setting of surgery or shortly after surgery using LP and manometry. In the presence of increased ICT, we recommend a permanent CSF diversion as an adjuvant treatment to the repair of the defect. Our series suggests that patients with increased ICT can be identified and managed early, thus avoiding recurrence and another operation. Further prospective, randomized, controlled trials are recommended to determine the need for permanent CSF diversion in such patients.

\section{Conflicts of Interest}

The authors declare no conflicts of interest regarding the publication of this paper.

\section{References}

[1] Lindstrom, D.R., Toohill, R.J., Loehrl, T.A. and Smith, T.L. (2004) Management of Cerebrospinal Fluid Rhinorrhea: The Medical College of Wisconsin Experience. The Laryngoscope, 114, 969-974. 
https://doi.org/10.1097/00005537-200406000-00003

[2] Park, J.-I., Strelzow, V.V. and Friedman, W.H. (1983) Current Management of Cerebrospinal Fluid Rhinorrhea. The Laryngoscope, 93, 1294-1300.

https://doi.org/10.1002/lary.1983.93.10.1294

[3] Woodworth, B.A., Prince, A., Chiu, A.G., et al. (2008) Spontaneous CSF Leaks: A Paradigm for Definitive Repair and Management of Intracranial Hypertension. Otolaryngology_Head and Neck Surgery, 138, 715-720. https://doi.org/10.1016/j.otohns.2008.02.010

[4] Clark, D., Bullock, P., Hui, T. and Firth, J. (1994) Benign Intracranial Hypertension: A Cause of CSF Rhinorrhoea. Journal of Neurology, Neurosurgery, and Psychiatry, 57, 847-849. https://doi.org/10.1136/jnnp.57.7.847

[5] Yang, Z., Wang, B., Wang, C. and Liu, P. (2011) Primary Spontaneous Cerebrospinal Fluid Rhinorrhea: A Symptom of Idiopathic Intracranial Hypertension? Journal of Neurosurgery, 115, 165-170. https://doi.org/10.3171/2011.3.JNS101447

[6] Schlosser, R.J., Wilensky, E.M., Grady, M.S. and Bolger, W.E. (2003) Elevated Intracranial Pressures in Spontaneous Cerebrospinal Fluid Leaks. American Journal of Rhinology, 17, 191-195. https://doi.org/10.1177/194589240301700403

[7] Schlosser, R.J., Woodworth, B.A., Wilensky, E.M., Grady, M.S. and Bolger, W.E. (2006) Spontaneous Cerebrospinal Fluid Leaks: A Variant of Benign Intracranial Hypertension. Annals of Otology, Rhinology, and Laryngology, 115, 495-500. https://doi.org/10.1177/000348940611500703

[8] Suryadevara, A.C., Fattal, M. and Woods, C.I. (2007) Nontraumatic Cerebrospinal Fluid Rhinorrhea as a Result of Pseudotumor Cerebri. American Journal of Otolaryngology, 28, 242-246. https://doi.org/10.1016/j.amjoto.2006.08.013

[9] Brainard, L., Chen, D.A., Aziz, K.M. and Hillman, T.A. (2012) Association of Benign Intracranial Hypertension and Spontaneous Encephalocele with Cerebrospinal Fluid Leak. Otology \& Neurotology, 33, 1621-1624. https://doi.org/10.1097/MAO.0b013e318271c312

[10] Rudnick, E. and Sismanis, A. (2005) Pulsatile Tinnitus and Spontaneous Cerebrospinal Fluid Rhinorrhea: Indicators of Benign Intracranial Hypertension Syndrome. Otology \& Neurotology, 26, 166-168. https://doi.org/10.1097/00129492-200503000-00006

[11] Mokri, B. (2002) Intracranial Hypertension after Treatment of Spontaneous Cerebrospinal Fluid Leaks. Mayo Clinic Proceedings, 77, 1241-1246. https://doi.org/10.4065/77.11.1241

[12] Woodworth, B.A. and Palmer, J.N. (2009) Spontaneous Cerebrospinal Fluid Leaks. Current Opinion in Otolaryngology \& Head and Neck Surgery, 17, 59. https://doi.org/10.1097/MOO.0b013e3283200017

[13] Chaaban, M.R., Illing, E., Riley, K.O. and Woodworth, B.A. (2013) Acetazolamide for High Intracranial Pressure Cerebrospinal Fluid Leaks. International Forum of Allergy \& Rhinology, 3, 718-721. https://doi.org/10.1002/alr.21188

[14] Caballero, N., Bhalla, V., Stankiewicz, J.A. and Welch, K.C. (2012) Effect of Lumbar Drain Placement on Recurrence of Cerebrospinal Rhinorrhea after Endoscopic Repair. International Forum of Allergy \& Rhinology, 2, 222-226. https://doi.org/10.1002/alr.21023

[15] Carrau, R.L., Snyderman, C.H. and Kassam, A.B. (2005) The Management of Cerebrospinal Fluid Leaks in Patients at Risk for High-Pressure Hydrocephalus. Laryngoscope, 115, 205-212. https://doi.org/10.1097/01.mlg.0000154719.62668.70 
[16] Schlosser, R.J., Wilensky, E.M., Grady, M.S., Palmer, J.N., Kennedy, D.W. and Bolger, W.E. (2004) Cerebrospinal Fluid Pressure Monitoring after Repair of Cerebrospinal Fluid Leaks. Otolaryngology_Head and Neck Surgery, 130, 443-448. https://doi.org/10.1016/j.otohns.2003.12.018

[17] Wang, E.W., Vandergrift, W.A. and Schlosser, R.J. (2011) Spontaneous CSF Leaks. Otolaryngologic Clinics of North America, 44, 845-856. https://doi.org/10.1016/j.otc.2011.06.018

[18] Virk, J.S., Elmiyeh, B. and Saleh, H.A. (2013) Endoscopic Management of Cerebrospinal Fluid Rhinorrhea: The Charing Cross Experience. Journal of Neurological Surgery. Part B, Skull Base, 74, 61-67. https://doi.org/10.1055/s-0033-1333620

[19] Deenadayal, D.S., Kumar, B.N. and Vyshanavi, B. (2016) CSF Rhinorrhoea-100 \% Success Rate: What Do We Do. IOSR-JDMS, 15, 58-61.

[20] Sarkar, A. and Sharma, N. (2016) Spontaneous CSF Rhinorrhea Our Experience. Indian Journal of Otolaryngology and Head \& Neck Surgery, 68, 126-129. https://doi.org/10.1007/s12070-015-0963-Z 